\title{
Performance measurement and management in the British higher education sector
}

\author{
Abdullah Zafar Sheikh ${ }^{1}$. John Chandler ${ }^{2}$ - Basharat Hussain ${ }^{3,4} \cdot$ Stephen Timmons ${ }^{5}$
}

Accepted: 27 January 2022 / Published online: 21 February 2022

(c) The Author(s), under exclusive licence to Springer Nature B.V. 2022

\begin{abstract}
Theoretical enquiry and empirical studies demonstrate the significance of performance management (PM) in the higher education sector and it is a fulcrum for developing a strategic role for people management within universities. In spite of the perceived weaknesses of people management in the higher education sector, in general, the current period of rapid and substantial contextual change may necessitate greater formalisation of HR practices across the British higher education sector. In addition to the changing role of the HR function and line managers, these developments may result in an increasingly stringent performance regime across the sector, especially in more hard-pressed institutions. Through a literature review and a pilot study, this paper attempts to address two main research questions: (i) what are the current performance management practices in the British Higher Education sector? and (ii) what needs to be done to strategically align these practices within HEIs in the UK? This paper discusses the wider literature related to performance management in general and to academic institutions in particular. We also undertook a small-scale qualitative study to explore the views of HR professionals on the need for, and the current performance measurement systems in their universities in the UK. The preliminary findings confirmed that PM is a key issue in the respondents' institutions, with substantial and recent changes in policy. This underscores the need for a large-scale research agenda to capture the current dynamics of change the sector is undergoing. The paper concludes by stimulating a policy debate and placing a number of research calls, along with suggestions on how these research questions may be investigated.
\end{abstract}

Keywords Performance management $\cdot$ Human resource strategies $\cdot$ Higher education sector $\cdot$ UK

\section{Introduction}

The British higher education sector is currently going through an unprecedented transformation (Hutaibat et al. 2021a, b). Shrinking public funding, together with the new fees regime introduced by an overwhelming majority of British universities is creating

Basharat Hussain

Basharat.hussain@umt.edu.pk

Extended author information available on the last page of the article 
significant financial pressure on the British higher education sector (Hutaibat et al. 2021a, b). As students pay more, they expect more in terms of academic quality and employability. Due to the ongoing Covid-19 pandemic, international students are also less likely to come to the UK. Brexit has further unsettled UK HEIs- with the actual and prospective loss of European Union level grants and EU student enrolment. Funding for research grants, is now very competitive and is spread more thinly. Furthermore, governments are no longer exclusively interested in the importance of research for academic purposes but now also consider its importance for other sectors of society such as economic or cultural (Gralka, 2019). All these challenges together will provide a major stimulus to significant shifts in the pattern of Human Resource (HR) practices observed across the UK's higher education sector. The emphasis placed on greater HR sophistication in the last decade, generously funded by HEFCE (Higher Education Funding Council for England) and other sources is moving to one based on cost-cutting and a greater reliance on precarious academic labour.

It can be argued that such changes have led universities to act more like business enterprises than traditional educational institutions (Clarke and Knights 2015; Lynch 2015; Burnes et al., 2014), as a step, in effect, towards the sector's privatisation (Lynch 2015). The reorganisation of universities' academic structures to become more market responsive and to satisfy the growing expectations of stakeholders (Hutaibat et al. 2021a, b; Clarke and Knights 2015; Lynch 2015; Bleiklie and Kogan 2007) has led, for some, to an increased managerialism (Clarke and Knights 2015; Lynch 2015; Deem et al. 2007) and a persistent weakening of the academic voice (Shattock, 2013). Academic departments have been transformed into business units with a focus on business targets, working within rigid budgetary constraints (Clarke and Knights 2015; Lynch 2015; Waring 2017). For instance, a number of British higher education institutions have now adopted the practice of offering teaching-only contracts to poor or non-active researchers. It is noted that increase in managerialism has also resulted in giving more financial and administrative powers to administrators, which has subsequently resulted in academic members of staff feeling more dominated and marginalized (Mkasiwa 2020). In this paper we are thus seeking to answer two research questions: i) what are the current performance management practices in the British Higher Education sector? and ii) what needs to be done to strategically align these practices within HEIs in the UK?

\section{Methodology}

As this paper draws on both the literature and an empirical pilot study for its findings, the literature review is presented first. Details on how the pilot study was carried out are given below (under 'Pilot Study'). The paper first scoped the relevant literature on the topic. Both theoretical and empirical literature related to performance management in HEIs is presented. Based on this a qualitative pilot study was carried out to establish relevant research questions for future research.

\section{Literature review}

Market pressures, coupled with the growing importance of university rankings and league tables have, in theory at least, required considerable attention to be given to the performance of academic staff (Lynch 2015;Ter Bogt and Scapens, 2012). Evidence suggests that 
the underdevelopment of people management in the HE sector, confronted with a period of rapid and substantial contextual change, will necessitate greater formalisation of HR practices, including changes to the HR function, middle and first-line management and, especially, the more systematic management of the resourcing and performance of academics. In their survey of nearly 50 HEIs (Guest and Clinton 2007) performance management was only the sixth most frequently listed 'greatest HR challenge' (Guarini et al. 2020), but it was much the most frequently cited HR priority for the respondents (who were generally HR directors). Performance management remains the area within HRM practice that requires more attention to be managed effectively (Decramer et al. 2013). This was reflected in a widespread failure to deal with poor performance in particular (Decramer et al. 2013), as well as illustrative of a relatively primitive set of HR systems (Clarke and Knights 2015) in HE, notwithstanding large-scale and continuous investment in change over the last decade. This expenditure had largely concentrated on traditional personnel policies and areas, such as elaborate job evaluation schemes and managing conflict in employee relations. Other developments have been hampered by often "part-time, shortterm and amateur managers" that rarely give "a high priority to applying HRM" (ibid: 39), erecting a major barrier to the deployment of effective or mature systems of performance management.

This is the HE instance of the paradigm of public management system called New Public Management (NPM). NPM has roots in the 1890s system of 'modern Taylorism', which Frederick Winslow Taylor introduced as a management system known for its performance measurement and incentive-driven performance, and later in the 1980s, NPM evolved due to taking up ideas from the new institutional economics (Hood 1990). Hood (1990) identified the importance of context within the NPM however, some general features remain typical such as a greater emphasis on management and institutional design (Iacovino et al. 2017), output controls, differentiation, and subsidiary.

\section{Problems in performance management}

The systematic and unintended consequences of the adoption of external Performance Management System (PMS) can be categorized into three sections based upon the nature of the problems arising: systematic consequences, human capital-related consequences, and reduced quality. Guarini et al. (2020) reported a case of adoption of an external PMS, the adoption of National Italian NPM model known as VQR by an Italian university, without any institutional adjustments to the internal PMS at the organizational level. took the form of an Internal Departmental Ranking on the basis of which both academics and their respective departments were to receive career advancement and resource allocation. Such an isomorphic interaction generated two types of unintended consequences for the overall NPM: shifting focus away from teaching and third-mission activities due to an increased emphasis on research performance; and, research becoming irrelevant for domestic stakeholders in order to engage international stakeholders. With the implementation of calculative practices in public universities, many changes related to power dynamics occurred including increased horizontal links among the working groups related to Knowledge Balance Sheets (KBS) at the organizational level (Habersam et al. 2020). The government's enhanced political control over HE and increased adoption of horizontal coordination resulted in transformed organizations where NPM with old public administration elements combined with post-NPM resulting into new compound and hybridized organizations with 
co-existing combinations of governance and other reform features (Christensen 2012). Grossi et al. (2020a, b) considered performance management in KIPOs (knowledge-intensive public organizations offering services by experts for public-value creation) and concluded that Performance Management is much more complex in hybridized organizations due to the conflicting values and institutional logics internal to the nature of these organizations. Therefore, performance management cannot be regarded as neutral. The reactions and attitudes of different internal actors, and different organizational factors like culture, size and ownership, leadership and the maturity of performance management, have a strong bearing on the appropriate utilization of the tool (Dobija et al. 2019a, b). However, in terms of impact, NPM is a neutral system that may produce outcomes of either nature, positive or negative, depending upon various factors. The organization may receive either positive or negative effects depending upon the juxtaposition of significant challenges due to external or internal events and possibility of some unintended consequences of the system (Rigby et al. 2021). The study by Franco-Santos and Doherty (2017), in a British context, considered two models of performance management: direct based on agency theory and an enabling model based on stewardship theory. The study showed nearly contrary results for both models. In the case of the direct model, complex dynamics emerged in the findings between performance management and employees' well-being in the academic contexts. The perceived use of directive performance management practices such as performance measures and targets increase vitality and stress in employees.

Studies have indicated NPM causing excessive workload for academics. The assertive nature of HR functions continues to control line managers' 'highly variable' behaviour (Guarini et al. 2020; Hutaibat et al. 2021a, b), with 'harder measures' (Clarke and Knights 2015). The major issue in implementation of Performance Management systems in academia is its data-driven nature. Kallio and Kallio (2014), in a Finnish context, concluded that Management by Results (MBR) was not compatible with academia, and, at worst, negatively impacts academics' intrinsic motivation. The majority of academics related quality to autonomy. Most academics' goal is content creation that is creative and meaningful rather than incentive-driven (Kallio and Kallio 2014). Academia had been following a professional bureaucracy model that provided freedom for academics to manage their own work but MBR is restrictive (Kallio and Kallio 2014). Martin-Sardesai and Guthrie (2018) also found highly de-motivating effects of a more control-oriented performance management approach over human capital (HC). The performance management system found causing fear and anxiety among employees resulting into gaming and strategic initiatives with increased workload focusing more on research quantity than quality, which overall resulted into loss of HC (Martin-Sardesai and Guthrie 2018). Such loss of HC may disrupt the social and economic situation and may ultimately result in reduced funding to the university from the government (Martin-Sardesai and Guthrie 2018). Moreover, the increased demand pressure on the individuals in the form of competition, expected outcomes, and reduced funding promoted intense working environments, more competitive settings, and increased expectations. Furthermore, the culture of objectivity does not necessarily generate optimal outcomes. For instance, Student Evaluation of Teaching (SET) is an important element with regard to the evaluation of academics. Esarey and Valdes (2020) demonstrated the erroneous nature of SET under ideal (statistical) assumptions, resulting into high error rates. These included unreliable results in pairwise comparison due to large variances in SET responses, and differences in overall evaluation results and any specific variable such as instructional quality. Despite being an imperfect measure for evaluating teachers' performance, SET continues to be incorporated due to its low-cost and standardization advantages over other alternatives (Hornstein 2017; Esarey and Valdes 2020). 
When it comes to academics' response to NPM, many researchers reported a common behaviour 'adjustment' in academics in response to different Performance Management models. Guarini et al. (2020) presented three different ways in which academics responded to this adoption: there was no change in their routines; there were efforts to conform and adapt to the system; or they completely ignored the criteria. Academics' responses towards a meritocratic system for PM included 'many' who were 'disturbed by the system' and 'a few' who wanted to 'disturb the system' (Clarke and Knights 2015). Habersam et al. (2020) called it a culture rather than a behaviour, which consisted of 'new communicative practices' emerging as a reaction at horizontal level within the organizational level. This new culture (open resistance for persuasion and symbolic use) allowed the continuous use of managerialism despite being heavily criticised for its dysfunctional effects. Symbolic use referred to practicing just for the sake of performing the act without identifying with it. However, Clarke and Knights (2015) pointed to a status quo in favour of an increased emphasis on research performance and a focus on career advancement (Guarini et al. 2020) and hyper-individualism (Clarke and Knights 2015). This was mainly because the reinforcement found between performance measurement systems' logics and some disciplines' research traditions (especially 'hard' sciences) hinted at the interplay of power and an element of politics in action at the departmental level (Guarini et al. 2020). But overall, academics perceived and interpreted the performance management as of 'squeezing in' something much complex, dynamic, and diverse into a common and rigid grid of metrics (Woelert and Yates 2015).

According to Woelert and Yates (2015), the emphasis on performance measurement within academia (such as consequential, template, metric-based, and centralised) indicates little trust by political authorities in HE in terms of delivery. Dobija et al (2019a, b) identified three stakeholders with differing authorities and power to impact performance management systems in HEI business schools: funding bodies, professional groups, and purchasers. Among the three, the funding bodies and professional groups hold the greater power to influence. As the public sector is mainly funded by government it serves as an information provider for the government. In case of private sector institutions, both stakeholders have strong influence. Moreover, performance management in the private sector is highly effected by the type of accreditation (either little-known accreditation agencies or renowned global accreditation agencies, such as AACSB, EQUIS or SACSCOC etc.) employed by the university. The performance management system is designed to respond to performance expectations of accreditation agencies (Dobija et al 2019a, b). With reduced differences between public and market interests, ranking has resulted not only into "privatisation' of knowledge through presenting no incentive on playing the role of a public intellectual or caring teacher, but it also limits the learning opportunities rising due to interaction between theoretical and experiential knowledge (Lynch 2015), resulting into reduced quality. For the same reason the audit culture in hybridized universities is looked upon in a negative light by various disciplines including accounting, management, and education. Although these calculative practices (such as annual staff reviews, mission statements, and output performance indicators) were adopted with the aim of improving quality in university performance (such as education, research, and knowledge dissemination) however, such quantification resulted into reduced quality, affected collegiality and limited academic freedom (Argento et al. 2020). Cadez et al. (2017) explained the same issue by probing into the matter statistically and found that the research quality and teaching quality were positively correlated while no correlation was found between research productivity and teaching quality. Moreover, research-based evaluations of performance may result in reduced quality of teaching. 
Furthermore, implementing policy into effective practice remains a major challenge (Pechmann and Haase 2021). These performance measures have become highly politicised in so far as there is a duality in the design of measures such as 'management tools' and at the same time they are 'performance tools of public expression' (Cave et al. 1995). This duality is derived from government policies which also play a dual function. On the one hand these policies advocate quality measurements while at the same time they have complicated the concept of quality and raised questions over performance management questioning what good performance is (Cave et al. 1995). Performance Management remains fragmented and undefined (Bloch et al. 2021). One major reason may be the lack of genuine attention by policy makers to performance quality, especially in terms of defining it (Pechmann and Haase 2021). Goh (2012) has also argued that the existing issues relating to performance measurement and management implementation is due to lack in focus. The recent use of the word 'quality' by policy makers has evolved it into a multi-purpose word that not only supports Higher Education (HE) policy making but also supports political and ideological arguments regarding policy design. It is also found serving as a 'HE relevance tool' fulfilling businesses' demands of producing market competitive (accordingly competitive employees) graduates while keeping HE relevant to businesses. Recent practices focused upon quality can be divided into two categories. The first is 'promoting knowledge reflection and transfer' and 'promoting feedback and observation processes' (Bloch et al. 2021). The second category involved competence development programmes focused mostly on initiatives such as promoting an active role for students in learning (Bloch et al. 2021). According to Pechmann and Haase (2021), this continued existential crisis of 'quality' seemed to benefit policy makers as it is such a broadly defined and used term. However, researchers need to define quality for improvement in HE.

\section{Solutions for performance management}

Keeping the context-specific nature of NPM (Hood 1990) in mind, there has been a great deal of attention paid, over the last decade, to emerging contours of performance management of academic staff across varying national contexts. For instance, Dobija et al. (2019a, b), in a Polish context, analysed two ways (rational and symbolic) in which performance management was found in use. Performance management used as a rational tool to translate individuals' performance into metrics to rate them as weak or strong. The trend was followed to the department and the institution. On the other hand, performance management as a symbolic tool works on the grounds of internal transparency mainly for reputation and image building before external stakeholders at both individual and departmental levels. Camilleri (2021), in a South European context, presented the Balanced Scored Card (BSC) as a tool for evaluating teaching performance, research performance, career advancement, and financial performance. Guarini et al. (2020) studied NPM in theItalian context where the Italian National NPM model has been used in the Italian HE system since early 2000s by both management and academics. The National Agency for the Evaluation of Universities \& Research Institutes (ANVUR) was established in 2011 based on a research assessment framework (VQR) to evaluate universities' performance. The Italian university had adopted its government's (external) NPM model for its (internal) performance evaluation at the organizational level (Guarini et al. 2020). Despite being contradictory in nature both logics, business and academic, were found to mutually strengthen each other using the VQR model. In the British context, Franco-Santos and Doherty (2017), observed two 
models of performance management. These models include: Direct based on Agency theory, and Enabling based on Stewardship theory. The authors observed the impact of both models in presence of 'perceptions of employees regarding their experience of work' as mediator. These perceptions were based on how academics perceived job demands, job control, and management support. Contrary to the directive model, the perceived use of enabling performance management (such as resources, greater consultation, opportunities for development, excellence recognition, and communication) improved well-being directly impacting vitality and indirectly improved the stress levels. Consequently, the performance management systems needs to be compatible with organizational culture considering $\mathrm{HC}$ as well to implement appropriate performance tools at the organizational level (Hutaibat et al. 2021a, b). There has been increasing research on performance management in British HEIs since 2001 which presented various effective approaches to implement a well-adjusted NPM: employee perspective (Decramer et al. 2013), student-centred teaching, organizational capacity perspective and Balanced Scored Card's (BSC) financial perspective (Camilleri 2021).

Publicly funded research into British HE developments argues for a fuller role for HRM. There is a need to create and maintain balance in the workload over academics focusing all of the three tasks: quality teaching, research performance, and other activities (Guarini et al. 2020; Hutaibat et al. 2021a, b), with the expansion in the range of academics' task load invited more attention towards boosting academic productivity through focusing performance management, workload allocation and other such resources and systems (Camilleri 2021). More flexible responses to students' demands for improved access to staff and more formal planning and measurement of academics' activities are also seen as widespread implications of institutional strategies in a changing sectoral context. This postulated enhanced role for better management of performance in the HE sector also finds an echo in the more general literature. Research showed that performance management at the centre of academics work life (Hutaibat et al. 2021a, b), with changing cultural and environmental conditions (Guarini et al. 2020), dealt with 'hard measures' (Clarke and Knights 2015). Stein et al. (2019) highlighted three factors that can play a role in providing meaningfulness to any datafication work experience: a) the design that accountability systems follows along with characteristics of datafication of work, b) the institutional context in which that system operates, c) the responses adopted as appropriate to retain the meaningfulness of any particular datafication work experience. Other than this, some of the main enabling mechanisms included consultation, information sharing, and communication along with model refinement and adjustments (Rigby et al. 2021). Furthermore, these hard measures tend to direct employees' behaviours. A survey by Decramer et al. (2013) focused upon contributions by individuals to their organizations' objectives in the form of compliant behaviour, capability, and performance. Increasingly organisations are promoting compliant behaviour and expecting their employees behave in a certain manner. Now, organisations are also concerned about the process through which outputs are generated rather than focusing only the outputs (Clarke and Knights 2015). This more nuanced and inclusive approach promises success, especially when it is applied to knowledge workers whose interactions with clients often demand sophisticated behavioural routines to achieve the required levels of service (Clarke and Knights 2015). There are obvious normative assumptions about the content and practice of performance management, which have specific resonances for staff in $\mathrm{HE}$.

As per conventional wisdom, an appropriate, fair, systematic, intelligent, effective and motivating performance management system is needed by HEIs. Tjahjadi et al. (2019) explained a positive association between performance management system and 
public Higher Education Institutions (HEIs) organizational performance having Intellectual Capital (IC) as the mediator which was found mediating this positive association partially. Therefore, strengthened IC via improved performance management systems has beneficial implications for the organizations. Depending upon structural (includes explicit knowledge about different aspects of organization: promotion, communication etc.; and technological resources) and relational capital (an organization's relations with its environment i.e. an institution's relationships with other HEIs, stakeholders, and its reputation), the Intellectual Capital of Higher Education Institutions (ICHEIs) influence the institution's performance positively (de Matos Pedro et al. 2020). Furthermore, Mabaso and Dlamini (2018) concluded that both performance management and total rewards are positively correlated with organizational commitment. Moreover, Goh (2012) presented three important factors: learning and evaluation-centred organizational culture, increased managerial discretion, and involvement of stakeholders to have significant influence as necessary for the effective implementation of performance management systems. Considering the involvement of stakeholders, Decramer et al. (2013) emphasized the role of employees and advocated the incorporation of employees' perspective while examining performance management. A higher level of employees' satisfaction within performance management systems was found to be achievable if the performance management system had great internal consistency, tight control, and positively-perceived communication at both ends (Decramer et al. 2013).

Therefore, according to Martin-Sardesai et al. (2020), there is a need to take practical steps for the effective implementation of performance management systems rather than taking universities back to traditional setups. They highlighted the urgent need for strategic responses to configure expectations from academic work again. They also indicated the need for new approaches: distributing academic work among the staff, perceptions regarding academic work and the value attached with it, along with recognition and rewarding of achievements. Moreover, to prevent the loss of academics, universities need to consider working conditions, rewards, and efforts to deal with pressures balancing maintenance of teaching quality with research productivity. Esarey and Valdes (2020) suggesting a need for more nuanced approaches to replace SET such as peer evaluation as an effective tool to evaluate performance in 'teaching'. Compensation systems and performance appraisals can be used for motivating academics and directing their activities in accordance with HRM and strategic plans of the institutions (Allui and Sahni 2016). The incorporation of the concept of 'public good' has been proven successful in handling the increased demand for public accountability from HE and re-positioning HE (Hazelkorn and Gibson 2019). Decramer et al. (2013) argued for 'effective performance management' as crucial for developing a high quality and successful HE workforce. In a recent study of British Universities' HR professionals, Mansour et al. (2015) found that respondents were keen to reorient their institutions towards a more top-down form of organization, suggesting a move away from a more traditional view of universities as participatory institutions. The concepts of careering, and attachment of reward and failure with scholarly activities, resulted in material as well as symbolic success. These were found to reduce resistance among academics against the 'meritocratic' performance measurement system.In a public management context, Iacovino et al. (2017) indicated the need for implementation of performance management in the public sector to achieve service quality, savings on public spending, efficient administration and effective implementation of public policy. 


\subsection{A contextual framework for the diversification of HRM in universities}

Any such consideration must be influenced by the increased diversification in strategy and mission among HEIs (Hutaibat et al. 2021a, b), albeit located within general concerns about balancing of teaching and research activity (Clarke and Knights 2015; Guarini et al. 2020); winning new revenue streams (Guarini et al. 2020); stronger international profiles, and, improved and fairer access for students (Hutaibat et al. 2021a, b). This diversity is tackled by different institutional strategies, related to the academic and business portfolio that expresses the distinctive identity of an HEI. The portfolio comprises the position within different income streams available to the sector: 'public research' (HEFCE QR grants etc.), 'private research' (contracts from private and public sources), 'publicly funded teaching' (mainly HEFCE T grants, primarily defunct from 2012/13), 'privately funded teaching' (unregulated fees), 'academic enterprise' (IP commercialisation and consultancy) and 'other services' (catering, accommodation, lettings and other revenue generation). Institutions' patterns of revenue from these sources will vary widely, compounded by the different 'market positioning' adopted in each of these business areas, such as 'international', 'national' and 'local' sources of demand and funding (Dobija et al. 2019a, b; Hutaibat et al. 2021a, b).

This varying dependence on different income streams and various stakeholders to which an institution is exposed is synthesised into five relatively independent categories of institutional strategy: 'primary research' (a world-class reputation in primary research), 'research-led teaching' ('international recognition for research-informed education'), 'professional formation' (emphasis on research-informed practice), 'researchbased solutions' (for international and national clients) and 'specialist/niche provision' (Dobija et al. 2019a, b). Each category brings with it specific environmental drivers and related critical success factors, informing in turn the key capabilities required of the organisation. It is within this strategic context that workforce requirements are shaped, encompassing numbers, demographic profile, skill-set, working arrangements and employment structures. These are matched with institutional strategies through recruitment and retention.

This model has important implications for the nature and quality of managerial leadership at different organisational levels, as well as an impact on specific HR strategies and practices. While some developments are seen as common to all institutional strategies, such as a broadening of academic responsibilities and, with it, greater resource and performance management of lecturers, others depend on the specific demands of an overarching business strategy. As such, a relatively powerful model is offered, capturing differentiation in HR practices and their primary drivers. Nevertheless, its top-down linearity and implicit determinism are two potential criticisms, as is its tendency to treat HEIs as principally 'U-form' structures, rather than complex, multidivisional organisations whose faculties may pursue distinctive business and HR strategies. This is certainly commensurate with the business unit level of analysis typical of the strategy literature. Moreover, the designation of 'outdated policies for industrial relations' and 'unwieldy decision-making procedures' (Iacovino et al. 2017), together with the obstruction to 'agility and flexibility' posed by the single grading and pay framework, national pay bargaining and standard terms of employment (Iacovino et al. 2017), all suggest a unitarist perspective that underplay issues of resistance and identity formation among academics.

Substantial barriers remain to the enhanced managerial direction of academics' performance, especially the emblematic cultural norm of academic autonomy, showing the 
centrality of agency (Clarke and Knights 2015; Guarini et al. 2020), and of the negotiation to outcomes (Guarini et al. 2020). Evidence of poorly developed line management (Guest and Clinton 2007) and its incapacity or indifference to extending managerial control may also counter or moderate attempts by often embattled HR functions to increase the sophistication and efficacy of performance management systems. This is perhaps reflected in performance appraisal not being clearly embedded in other HR practices, with one group of case studies showing no link between promotion and appraisal (Guarini et al. 2020).

\section{Pilot study}

The multidivisional structure of HEIs strongly recommends a faculty level of analysis that captures any key strategic drivers of HRM beyond often more open-ended institutional goals. This domain also enables important details of a performance management system to be captured and analysed. Given the closeness of Business Schools to commercial practice, it is reasonable to suggest that they are likely to be at the forefront of relevant developments and, therefore, a fruitful locus of enquiry. It was, therefore, decided to consider Business Schools as our unit of analysis.

Five higher education institutions were selected for the telephone interviews. These institutions representing the two main tiers of the British higher education sector. This included three universities from pre-1992 institutions (the old cluster, including Russell Group universities) and post-1992 institutions (mostly ex-polytechnics). The identity of the institutions and respondents are not revealed for data protection reasons. Senior HR officials (including directors, in some cases) were interviewed from these five institutions. Key lines of inquiry in this phase were based on a number of preliminary questions such as (a) what is being done, in the universities, to improve (manage) the performance of academics? (b) Has PM policy changed recently in the respondents' institutions? Are any changes planned? (c) Is PM aligned with School/Faculty/Academic-departmental goals? (d) Are more metrics being used currently to manage performance of academic staff compared with 5 years ago? (e) Is there more focus on outcomes as opposed to inputs now compared with 5 years ago? (f) Is PM subject to negotiation with relevant unions recently or currently?

\section{Preliminary findings and discussions of pilot study}

A number of interesting themes emerged from this first phase of preliminary telephonic interviews. There appeared unanimity that PM is a key issue in the respondents' institutions, with substantial and recent changes in policy, procedure and practice across all institutions. This was in line with the suggestion, made earlier in the paper, that PM is a priority in the management of academic staff. The general emphasis, however, seemed developmental and 'positive', but there is also clear evidence of the increased incidence of harder or more quantitative measures that focus on output and metrics. In fact, all of the respondents acknowledged that there is now more stress on outcomes rather than inputs. There are mixed views on benefits of using managerial and accounting practices in measuring performance of HEIs or academics. Argento et al. (2020) noted that it is possible to achieve positive changes at organizational and individual level through such measures. On the other hand it is argued that metric fetishization, 
instead of improving higher education sector weakens the noble and socially minded visions of what a university should stand for (Spence, 2018).

One respondent even cited the employment of the Research Assessment Exercise (RAE) for restructuring and redundancies, as has already been seen among some London universities. Some reference was made to PMs use within workload modelling. These findings are at variance with the normative literature on PM, which argues for an increasing emphasis on the desired behaviour of employees. Furthermore, it is suggested that collegial ethos of judgement is more appropriate for measuring performance in HEIs rather than a managerialist ethos of quantifications and measurement (Spence 2018). The measures used vary between the 'old' and 'new' university respondents. For the former, the emphasis is, as perhaps expected, on the Research Excellence Framework (REF) and research citations, although two out of the three respondents from the old cluster mentioned the importance they attach to the National Student Survey (NSS) for student feedback. The REF is the system for assessing the quality of research in UK higher education institutions while the NSS is primarily used to assess students' satisfaction about the quality of teaching. Both of the respondents from the new cluster (ex-polytechnic) mentioned Key Performance Indicators (KPIs), suggesting a more formal and even comprehensive approach, adopting all 'multi-rater' sources of feedback. The data point to interesting 'strategic' dimensions of PM. All, though more particularly the old universities, demonstrate strategic integration in an 'internal' or 'horizontal' sense, with appraisal linked to development, promotion and reward (although the more precise meaning of the latter is not clear). However, the 'vertical' integration of PM with institutional strategic goals is significantly more varied. While there is some claim to 'top-to-bottom' alignment, others assess that there is patchy integration with institutional or even faculty or departmental goals. This is important because PM relies definitionally on a meaningful correspondence between individuals' objectives and wider business objectives.

Three out of the five respondents stated that the University and College Union (UCU) is hostile or militant towards their policies on performance management. The UCU is the largest trade union for academics, researchers and academic-related staff working in higher education throughout the UK. This clearly requires fuller investigation, offering resistance, 'negotiated order' and 'social exchange' theory as potentially fruitful lines of enquiry. The respondents' limited control over line management further argues for the difficulty of translating PM policy into embedded practice. The final major finding is the blanket exclusion of hourly paid staff from PM systems, reinforcing the depiction of this group of employees as a sub-stratum of academics with little formal connection to developmental and reward opportunities. These preliminary findings underscore the need for a large-scale research agenda, across the British higher education sector, to capture the changing contours of performance management regimes and its implications, particularly in response to the unprecedented upheavals the sector is undergoing.

The findings from the preliminary round of investigation set the stage for a profound policy debate and leads to the generation of the following research calls:

\section{Research questions}

1. What are the features of the performance management systems in place? For example, what criteria are used to evaluate individual or team performance, including the relative stress on outcomes versus inputs, such as demonstrating required behaviours. Sources 
of evaluative data from different raters, such as line managers, peers and students, will also be addressed, along with the frequency and length of performance appraisals

2. What are the outcomes of performance management? The emphasis of normative accounts on the developmental thrust of appraisals may be counter-posed in increasingly difficult economic circumstances by a growing incidence of performance review and evaluation, reflected in 'harder' or more quantifiable objectives. Morris et al. (op. cit.) found that the most popular use of performance data was in the management of poor performers, and its incidence may be increasing.

3. To what extent are the strategic goals of the institution and faculty inscribed in the objectives set for staff? Outcomes may produce evidence of a 'line of sight' from individual performance appraisals to organisational objectives, and demonstrate the recognition of the 'strategic capabilities' (HEFCE, February 2010) required to achieve them. Alternatively, appraisals may be highly individualised and dislocated from supervening concerns.

4. Is there evidence of the integration of performance appraisals with other HR practices? One would anticipate a close relationship with staff development, but a more sophisticated performance management system would also include integration with decisions about promotion and rewards in the fullest sense, thereby including work allocation

5. Are there major variations in the experience of performance management for different segments of the academic workforce? In particular, do part-time or temporary employees receive the same treatment, and what differences are there between age and experience cohorts?

6. Finally, how can the formation of performance management systems in HEIs be assessed to capture the current dynamics and direction of change? This will necessitate retrospective analysis of key processual elements, embracing managerial aims and intentions, sources of their moderation and resistance and influential contingencies in the experience of respondents. A range of theoretical perspectives are implied here, which include strategy formation in HRM (Boxall and Purcell, op. cit; Jackson and Schuler, 2000), 'performance norms' (Fenwick and Cordey-Hayes 2000) and labour process approaches (Knights 1990) with their foregrounding of employee resistance.

7. What role funding and accreditation agencies can play in the development of performance management in HEIs in the UK?

These above research questions are similar to recent recommendations highlighted by empirical studies. For example, Grossi et al (2020a, b) in their study highlighted that the future research should tackle the strategic responses universities employ in improving their organizational and individual performances in a context of varying competing pressures from the arena of higher education. They also suggested that further studies could also advance our understanding of other factors having bearing on these internal changes for academic members of staff. Moreover, future studies could include the role of key actors (academics, managers etc.) who enable changes (i.e., the institutional entrepreneurs) by considering their interests, role and pursuit for legitimacy. Likewise, Williamson et al (2020) argued that quantifications of teaching in higher education remains a key focus for future studies,

Dougherty and Natow (2020) focussed on neo-liberal theory driven outcomes in HEIs. The authors particularly raised questions on efficiency; for whom and for what in HEIs context? They also suggested examining if the gains in organizational efficiency 
and social functionality are reaped at the cost of harming those disadvantaged by systems of class, race, gender, and other inequalities in HEIs.

\section{Conclusion}

Rapid contextual changes and upheavals are likely to generate quite distinctive business contexts for higher education institutions in the United Kingdom (Hutaibat et al 2021a, b). These pressures are further compounded by the growing importance of university rankings and league tables and are likely to result in more stringent performance regimes across the sector, especially among hard-pressed institutions, thus shifting employment relations (Lynch et al 2015). The context in which each UK HEI operates will influence its choice of performance management mechanisms. Hence, a variegated approach might emerge necessitating a more systematic management of performance of academics leading to changes in performance regimes (Iacovino et al. 2017). This is of particular interest if these changes are likely to create resistance from the academic staff. This paper has attempted to invoke a policy debate and suggested a future research agenda for exploring the performance management system in place, and how the formation of performance management can be assessed, to capture the current dynamics of change in the British Higher Education sector.

\section{References}

Allui, A., Sahni, J.: Strategic human resource management in higher education institutions: empirical evidence from Saudi. Procedia. Soc. Behav. Sci. 235(October), 361-371 (2016). https://doi.org/10.1016/j. sbspro.2016.11.044

Argento, D., Dobija, D., Grossi, G.: The disillusion of calculative practices in academia. Qual. Res. Account. Manag. 17(1), 1-17 (2020). https://doi.org/10.1108/QRAM-12-2019-0130

Bleiklie, I. and Kogan, M.: Organization and governance of universities. High. Educ. Policy 20(4), 477-493 (2007).https://doi.org/10.1057/palgrave.hep.8300167

Bloch, C., et al.: Does quality work work? A systematic review of academic literature on quality initiatives in higher education. Assess. Eval. High. Educ. 46(5), 701-718 (2021). https://doi.org/10.1080/02602 938.2020.1813250

Burnes, B., Wend, P. and By, R.T.: The changing face of English universities: reinventing collegiality for the twenty-first century. Stud. High. Educ 39(6), 905-926 (2014).https://doi.org/10.1080/03075079.2012. 754858

Cadez, S., Dimovski, V., Zaman Groff, M.: Research, teaching and performance evaluation in academia: the salience of quality. Stud. High. Educ. 42(8), 1455-1473 (2017). https://doi.org/10.1080/03075079. 2015.1104659

Camilleri, M.A.: Using the balanced scorecard as a performance management tool in higher education. Manag. Educ. 35(1), 10-21 (2021). https://doi.org/10.1177/0892020620921412

Cave, M., Hanney, S., Henkel, M.: Performance measurement in higher education-revisited. Public Money Manag. 15(4), 17-23 (1995). https://doi.org/10.1080/09540969509387890

Christensen, T.: Post-NPM and Changing Public Governance. Meiji J. Polit. Sci. Econom. 1, 1-11 (2012)

Clarke, C.A., Knights, D.: Careering through academia: Securing identities or engaging ethical subjectivities? Human Relat. 68(12), 1865-1888 (2015). https://doi.org/10.1177/0018726715570978

de Matos Pedro, E., Alves, H., Leitão, J.: In search of intangible connections: intellectual capital, performance and quality of life in higher education institutions. High. Educ. (2020). https://doi.org/10.1007/ s10734-020-00653-9

Decramer, A., Smolders, C., Vanderstraeten, A.: Employee performance management culture and system features in higher education: relationship with employee performance management satisfaction. Int. J. Hum. Resour. Manag. 24(2), 352-371 (2013). https://doi.org/10.1080/09585192.2012.680602 
Deem, R., Hillyard, S., Reed, M. and Reed, M.: Knowledge, higher education, and the new managerialism: The changing management of UK universities. Oxford University Press (2007)

Dobija, D., et al.: Rational and symbolic uses of performance measurement: experiences from Polish universities. Account. Auditing Account. J. 32(3), 750-781 (2019a). https://doi.org/10.1108/ AAAJ-08-2017-3106

Dobija, D., Górska, A.M., Pikos, A.: The impact of accreditation agencies and other powerful stakeholders on the performance measurement in Polish universities. Balt. J. Manag. 14(1), 84-102 (2019b). https:// doi.org/10.1108/BJM-01-2018-0018

Dougherty, K.J., Natow, R.S.: Performance-based funding for higher education: how well does neoliberal theory capture neoliberal practice? High. Educ. 80(3), 457-478 (2020)

Esarey, J., Valdes, N.: Unbiased, reliable, and valid student evaluations can still be unfair. Assess. Eval. High. Educ. 45(8), 1106-1120 (2020). https://doi.org/10.1080/02602938.2020.1724875

Franco-Santos, M., Doherty, N.: Performance management and well-being: a close look at the changing nature of the UK higher education workplace. Int. J. Hum. Resour. Manag. 28(16), 2319-2350 (2017). https://doi.org/10.1080/09585192.2017.1334148

Gralka, S., Wohlrabe, K. and Bornmann, L.: How to measure research efficiency in higher education? Research grants vs. publication output. J. High. Educ. Policy. Manag 41(3), 322-341 (2019). https:// doi.org/10.1080/1360080X.2019.1588492

Goh, S.C.: Making performance measurement systems more effective in public sector organizations. Meas. Bus. Excell. 16(1), 31-42 (2012). https://doi.org/10.1108/13683041211204653

Grossi, G., et al.: Accounting, performance management systems and accountability changes in knowledge-intensive public organizations: a literature review and research agenda. Account. Auditing Account. J. 33(1), 256-280 (2020a). https://doi.org/10.1108/AAAJ-02-2019-3869

Guest, D.E. and Clinton, M.: Human resource management and university performance. Lead. Found. High. Educ (2007)

Grossi, G., Dobija, D., Strzelczyk, W.: The impact of competing institutional pressures and logics on the use of performance measurement in hybrid universities. Public Perform. Manag. Rev. 43(4), 818-844 (2020b)

Guarini, E., Magli, F., Francesconi, A.: Academic logics in changing performance measurement systems: an exploration in a university setting. Qual. Res. Account. Manag. 17(1), 109-142 (2020). https://doi.org/10.1108/QRAM-06-2019-0076

Habersam, M., Piber, M., Skoog, M.: Calculative regimes in the making: implementation and consequences in the context of Austrian public universities. Qual. Res. Account. Manag. 18(2), 169-194 (2020). https://doi.org/10.1108/QRAM-01-2019-0021

Hazelkorn, E., Gibson, A.: Public goods and public policy: what is public good, and who and what decides? High. Educ. 78(2), 257-271 (2019). https://doi.org/10.1007/s10734-018-0341-3

Hood, C.: De-sir humphreyfying the westminster model of bureaucracy: a new style of governance? Governance 3(2), 205-214 (1990). https://doi.org/10.1111/j.1468-0491.1990.tb00116.x

Hornstein, H.A.: Student evaluations of teaching are an inadequate assessment tool for evaluating faculty performance. Cogent Edu. (2017). https://doi.org/10.1080/2331186X.2017.1304016

Hutaibat, K., Alhatabat, Z., von Alberti-Alhtaybat, L., Al-Htaybat, K.: Performance habitus: performance management and measurement in UK higher education. Meas. Bus. Excell. 25(2), 171-188 (2021a). https://doi.org/10.1108/MBE-08-2019-0084

Hutaibat, K., et al.: Performance habitus: performance management and measurement in UK higher education. Meas. Bus. Excell. 25(2), 171-188 (2021b). https://doi.org/10.1108/MBE-08-2019-0084

Iacovino, N.M., Barsanti, S., Cinquini, L.: Public organizations between old public administration, new public management and public governance: the case of the Tuscany Region. Public Organization Review 17(1), 61-82 (2017). https://doi.org/10.1007/s11115-015-0327-x

Kallio, K.M., Kallio, T.J.: Management-by-results and performance measurement in universities - implications for work motivation. Stud. High. Educ. 39(4), 574-589 (2014). https://doi.org/10.1080/ 03075079.2012.709497

Knights, D.: Subjectivity, power and the labour process. In: Knights, D., Willmott, H. (eds.) Labour process theory, pp. 297-335. Palgrave Macmillan UK, London (1990). https://doi.org/10.1007/9781-349-20466-3_10

Lynch, K.: Control by numbers: new managerialism and ranking in higher education. Critical Studies in Education 56(2), 190-207 (2015). https://doi.org/10.1080/17508487.2014.949811

Lynch, J., Walker-Gibbs, B., Herbert, S.: Moving beyond a 'bums-on-seats' analysis of progress towards widening participation: reflections on the context, design and evaluation of an Australian government-funded mentoring programme. J. High. Educ. Policy Manag. 37(2), 144-158 (2015) 
Mabaso, C.M., Dlamini, B.I.: Total rewards and its effects on organisational commitment in higher education institutions. SA J. Hum. Resour. Manag. 16, 1-8 (2018). https://doi.org/10.4102/sajhrm. v16i0.913

Martin-Sardesai, A., Guthrie, J.: Human capital loss in an academic performance measurement system. J. Intellect. Cap. 19(1), 53-70 (2018). https://doi.org/10.1108/JIC-06-2017-0085

Martin-Sardesai, A., Guthrie, J., Tucker, B.P.: What you see depends on where you look: performance measurement of Australian accounting academics. Account. Auditing Account. J. 33(6), 1193-1218 (2020). https://doi.org/10.1108/AAAJ-08-2019-4133

Mansour, H.F., Heath, G. and Brannan, M.J.: Exploring the role of HR practitioners in pursuit of organizational effectiveness in higher education institutions. J. Change Manag 15(3), 210-230 (2015). https:// doi.org/10.1080/14697017.2015.1045539

Mkasiwa, T.A.: Budgetary practices in a Tanzanian University: Bourdieu's theory. J. Pub. Budg. Account. Financ. Manag (2020). https://doi.org/10.1108/JPBAFM-08-2019-0119

Pechmann, P., Haase, S.: How policy makers employ the term quality in higher education policymaking. Scand. J. Educ. Res. (2021). https://doi.org/10.1080/00313831.2020.1869081

Rigby, J., et al.: Implementing responsibility centre management in a higher educational institution. Int. J. Product. Perform. Manag. (2021). https://doi.org/10.1108/IJPPM-05-2020-0218

Stein, M.K., et al.: Datification and the pursuit of meaningfulness in work. J. Manage. Stud. 56(3), 685717 (2019). https://doi.org/10.1111/joms.12409

Shattock, M.: University governance, leadership and management in a decade of diversification and uncertainty. High. Educ. Q 67(3), 217-233 (2013).https://doi.org/10.1111/hequ.12017

Ter Bogt, H.J. and Scapens, R.W.: Performance management in universities: Effects of the transition to more quantitative measurement systems. Eur. Account. Rev 21(3), 451-497 (2012). https://doi.org/10. 1080/09638180.2012.668323

Tjahjadi, B., et al.: Does intellectual capital matter in performance management system-organizational performance relationship? experience of higher education institutions in Indonesia. J. Intellect. Cap. 20(4), 533-554 (2019). https://doi.org/10.1108/JIC-12-2018-0209

Waring, M.: Management and leadership in UK universities: exploring the possibilities of change. J. High. Educ. Policy. Manag 39(5), 540-558 (2017). https://doi.org/10.1080/1360080X.2017.1354754

Williamson, B., Bayne, S., Shay, S.: The datafication of teaching in higher education: critical issues and perspectives. Teach. High. Educ. 25(4), 351-365 (2020). https://doi.org/10.1080/13562517.2020.1748811

Woelert, P., Yates, L.: Too little and too much trust: performance measurement in Australian higher education. Crit. Stud. Educ 56(2), 175-189 (2015). https://doi.org/10.1080/17508487.2014.943776

Publisher's Note Springer Nature remains neutral with regard to jurisdictional claims in published maps and institutional affiliations.

\section{Authors and Affiliations}

\section{Abdullah Zafar Sheikh ${ }^{1}$ - John Chandler ${ }^{2}$ - Basharat Hussain ${ }^{3,4} \cdot$ Stephen Timmons $^{5}$}

Abdullah Zafar Sheikh

azsheikh@iba.edu.pk

John Chandler

j.p.chandler@uel.ac.uk

Stephen Timmons

Stephen.timmons@nottingham.ac.uk

1 Institute of Business Administration (IBA), Karachi, Pakistan

2 Royal Docks School of Business \& Law, University of East London, London, UK

3 University of Management and Technology (UMT), Lahore, Pakistan

4 Visiting Fellow, Nottingham University Business School, University of Nottingham, Nottingham, UK 
5 Nottingham University Business School, University of Nottingham, Jubilee Campus, Wollaton Road, Nottingham NG8 1BB, UK 